\title{
Estimation of cerebrospinal fluid cortisol level in tuberculous meningitis
}

Sir,

Mahale et al. addressed in their interesting study that the mean cerebrospinal fluid (CSF) cortisol level in tuberculous meningitis (TBM) patients was significantly higher as compared to aseptic meningitis patients and control subjects $(P<0.0001) \cdot{ }^{[1]}$ Accordingly, the authors suggested that CSF cortisol level estimation could be considered as a rapid, relatively inexpensive diagnostic marker in the early identification of TBM along with CSF findings of elevated proteins, hypoglycorrhachia, and lymphocytic pleocytosis. ${ }^{[1]}$ I presume that the clinical implication of that suggestion is questionable. This is based on the following two points.

First, the cut-off values of CSF cortisol were not established to be practically implementable in the Indian clinical setting.

Second, the use of biological markers, including adenosine deaminase (ADA) has been suggested to enhance the accuracy of the initial diagnosis of various infections, including meningitis. As a better alternative to CSF cortisol, I presume that CSF-ADA measurement could be considered as a simple, useful, and rapid diagnostic tool for the early recognition of TBM and evaluating anti-TB therapy in TBM patients in India. This is based on the following three points. (1) The accuracy of CSF-ADE has been recently studied in Indian TBM and non-TBM patients. The results indicated that CSF-ADA of $10 \mathrm{U} / \mathrm{L}$ as a cut-off value had $87.5 \%$ sensitivity and $83.3 \%$ specificity whereas the positive predictive value of the test was $87.5 \%$ and $83.3 \%$ negative predictive value. The study concluded that CSF-ADA estimation is not only simple, inexpensive, and rapid but also a fairly specific method for making a diagnosis of TBM, especially when there is a dilemma of differentiating tuberculous etiology from non-tuberculous ones. ${ }^{[2]}$ (2) Comparing ADA levels and polymerase chain reaction (PCR) in CSF has revealed that CSF-ADA is a more sensitive indicator than PCR for the diagnosis of TBM in an Indian cohort with suspected TBM. Using a cut-off level of $>10 \mathrm{U} / \mathrm{L}, \mathrm{CSF}-\mathrm{ADA}$ had the sensitivity of $92.5 \%$ and specificity of $97 \%$ for the diagnosis of TBM whereas PCR for TBM had a sensitivity of $44.5 \%$ and specificity $92 \%$ in the most likely TBM cases. $^{[3]}$ (3) Most recently, it has been found that even in low TB endemic areas, CSF-ADA measurement can be still used to early diagnose TBM. The best ADA cut-off in low TB endemic areas has been estimated to be $11.5 \mathrm{IU} / \mathrm{L}$ with $91 \%$ sensitivity and $77.7 \%$ specificity. If CSF-ADA (>11.5 IU/L) estimation is combined with CSF glucose level ( $<65 \mathrm{mg} / \mathrm{dL})$ and leukocytes $\left(\geq 13.5 \mathrm{cell} / \mathrm{mm}^{3}\right)$, the sensitivity and specificity will skip to $91 \%$ and $88 \%$, respectively. ${ }^{[4]}$

\section{Financial support and sponsorship}

Nil.

\section{Conflicts of interest}

There are no conflicts of interest.

Mahmood Dhahir Al-Mendalawi

Department of Paediatrics, Al-Kindy College of Medicine, Baghdad University, Baghdad, Iraq 
Address for correspondence: Prof. Mahmood Dhahir Al-Mendalawi, P. O. Box 55302, Baghdad Post Office, Baghdad, Iraq. E-mail: mdalmendalawi@yahoo.com

\section{References}

1. Mahale RR, Mehta A, Uchil S. Estimation of cerebrospinal fluid cortisol level in tuberculous meningitis. J Neurosci Rural Pract 2015;6:541-4.

2. Agarwal AK, Bansal S, Nand V. A hospital based study on estimation of adenosine deaminase activity (ADA) in cerebrospinal fluid (CSF) in various types of meningitis. J Clin Diagn Res 2014;8:73-6.

3. Rana SV, Chacko F, Lal V, Arora SK, Parbhakar S, Sharma SK, et al. To compare CSF adenosine deaminase levels and CSF-PCR for tuberculous meningitis. Clin Neurol Neurosurg 2010;112:424-30.

4. Parra-RuizJ,Ramos V,DueñasC,Coronado-ÁlvarezNM,Cabo-MagadánR, Portillo-Tuñón $\mathrm{V}$, et al. Rational application of adenosine deaminase activity in cerebrospinal fluid for the diagnosis of tuberculous meningitis. Infection 2015;43:531-5.
This is an open access article distributed under the terms of the Creative Commons Attribution-NonCommercial-ShareAlike 3.0 License, which allows others to remix, tweak, and build upon the work non-commercially, as long as the author is credited and the new creations are licensed under the identical terms.

\begin{tabular}{|l|l|}
\hline \multicolumn{2}{|c|}{ Access this article online } \\
\hline Quick Response Code: & Website: \\
\hline & www.ruralneuropractice.com \\
\cline { 2 - 2 } & \\
\hline & \\
\hline
\end{tabular}

How to cite this article: Al-Mendalawi MD. Estimation of cerebrospinal fluid cortisol level in tuberculous meningitis. J Neurosci Rural Pract 2016;7:329-30 